\title{
Limited surgical treatment of suspected necrotizing fasciitis of the upper extremity with a benign clinical presentation
}

\author{
Brian Gander MD ${ }^{1}$, Marc Kaye MD², Ronit Wollstein MD
}

B Gander, M Kaye, R Wollstein. Limited surgical treatment of suspected necrotizing fasciitis of the upper extremity with a benign clinical presentation. Can J Plast Surg 2012;20(3):e44-e46.

Necrotizing fasciitis is a rapidly evolving, potentially fatal infection. Current recommendations advocate antibiotic administration and early aggressive surgical debridement. Aggressive surgery is associated with significant morbidity, leaving patients with substantial tissue loss and complex wounds. A case of suspected necrotizing fasciitis treated with minimal surgery is described.

A previously healthy 48-year-old man presented with increased erythema, swelling and blistering of his left upper extremity. Despite a benign systemic clinical presentation, the hand and forearm were suspicious for necrotizing fasciitis, prompting surgical treatment. Surgical exploration found a significant amount of intradermal and subdermal clear fluid. It was decided to limit the amount of debridement. The diagnosis was Wells syndrome, eosinophilic cellulitis. Treated with steroids, the wounds healed uneventfully.

It is important to consider the complete clinical picture before aggressive surgical treatment. A negative history for diabetes, atypical clinical presentation and benign operative findings are suggestive of a more benign diagnosis.

Key Words: Necrotizing fasciitis; Surgical treatment; Wells syndrome

$\mathrm{N}$ ecrotizing fasciitis is a rapidly evolving, potentially fatal infection that is commonly polymicrobial. Typically comprised of Group A Streptococcus, Staphylococcus aureus and Escherichia coli, it is one of the few medical emergencies that require aggressive surgical treatment (1).

Annually, the Centers for Disease Control and Prevention (Georgia, USA) estimates 1500 new cases within the United Sates and, given that this infection may carry a variety of names (Fournier's gangrene, necrotizing cellulitis, hemolytic streptococcal gangrene, phagendena, hospital gangrene, etc), this figure is most likely an underestimate (2,3). Inciting events may range from previous abdominal surgery to minor trauma, and nearly $20 \%$ of cases have no clear site of entry (4). Symptoms on clinical presentation may also vary, from fever and cellulitis to palpable crepitus and bullae (5).

Radiographic images may identify subcutaneous gas and fine needle aspiration may also yield a positive Gram stain or frank pus. Timely diagnosis and treatment are paramount for favourable outcomes. Current treatment algorithms include broad spectrum antibiotic coverage in addition to early, aggressive surgical debridement.

While early treatment is mandatory, it is associated with significant morbidity. Aggressive debridement will leave a patient with substantial tissue loss and complex wounds. When the patient survives an upper limb infection, he/she will require complex flap coverage and sometimes prosthetics or hand transplantation for partial or complete limb loss.

We describe a case of suspected necrotizing fasciitis that was treated only with minimal surgery because of mild systemic symptoms. It is important to consider the complete clinical picture before aggressive surgical treatment.

\section{Le traitement chirurgical limité d'une fasciite nécrosante présumée d'un bras à la présentation bénigne}

La fasciite nécrosante est une infection à l'évolution rapide et au potentiel fatal. Selon les recommandations actuelles, il faut administrer des antibiotiques et procéder à un débridement chirurgical rapide et agressif. Une opération agressive s'associe à une morbidité élevée, qui laisse les patients avec une importante perte de tissus et des plaies complexes. Les auteurs décrivent un cas de fasciite nécrosante présumée traité au moyen d'une chirurgie minimale.

Un homme de 48 ans auparavant en santé a consulté en raison d'un érythème, d'un œedème et d'une vésication croissants du bras gauche. Malgré une présentation clinique systémique bénigne, la main et l'avantbras laissaient croire à une fasciite nécrosante, ce qui a suscité un traitement chirurgical. L'exploration chirurgicale a révélé une grande quantité de liquide intradermique et subdermique clair. Il a été entendu de limiter l'importance du débridement. On a posé un diagnostic de syndrome de Wells, ou cellulite à éosinophiles. Traitées aux stéroïdes, les plaies ont guéri sans incident.

Il est important d'envisager le bilan clinique complet avant d'entreprendre un traitement chirurgical agressif. Des antécédents négatifs de diabète, une présentation clinique atypique et des observations chirurgicales bénignes sont évocatrices d'un diagnostic plus bénin.

\section{CASE PRESENTATION}

A 48 year-old man presented with $12 \mathrm{~h}$ of increased erythema, swelling and blistering of his left upper extremity. His medical history was positive for traumatic brain injury, but otherwise negative for any systemic diseases such as diabetes or blood dyscrasia. Approximately two weeks before presentation, the patient, an employee of a local nursing home, developed a red pruritic rash and was seen by a local dermatologist. At that time, an ectoparasitic preparation was negative but the patient was diagnosed with scabies and treated with $5 \%$ permetherine cream from the neck down. Initially, five days of this treatment improved his symptoms; however, the swelling began to increase in his left upper extremity with increasing erythema and eventual blistering, which prompted the patient to present to the emergency department. On arrival, the patient denied any fevers or chills, and complained only of pruritus and some numbness in the left hand.

A physical examination was positive for significant edema and erythema descending from the mid-humerus to the finger tips. Additionally, multiple bullae were present from the antecubital fossa to the wrist, swelling proximal to the hand, blanching erythema throughout his forearm, decreased sensation in digits one, two and three, as well as crepitus (Figure 1). Radiographic studies of the affected extremity while in the emergency department demonstrated subcutaneous gas (Figure 2). Laboratory analysis was significant for a white blood cell count of nearly $18 \times 10^{9} / \mathrm{L}$. Broad spectrum antibiotics were started in addition to a prompt dermatological consult. The patient was then taken emergently to the operating room with the presumptive diagnosis of necrotizing fasciitis.

${ }^{1}$ Department of Surgery, Division of Plastic and Reconstructive Surgery; ${ }^{2}$ Department of Orthopedic Surgery, University of Pittsburgh Medical

Center, Pittsburgh, Pennsylvania, USA

Correspondence: Dr Ronit Wollstein, University of Pittsburg, 3550 Terrace Street, Pittsburg, Pennsylvania 15261, USA.

Telelphone 412-648-9657, fax 412-648-1987, e-mail wollsteinr@upmc.edu 


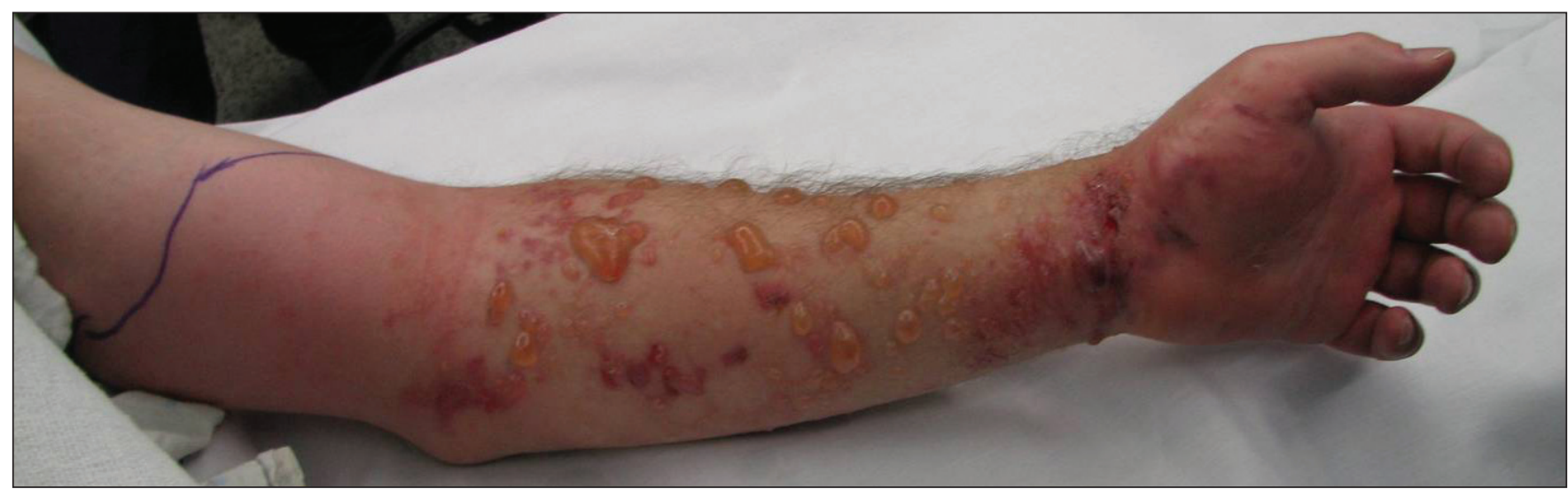

Figure 1) A clinical picture of the arm before surgery. The drawn line delineates the involved (red) area

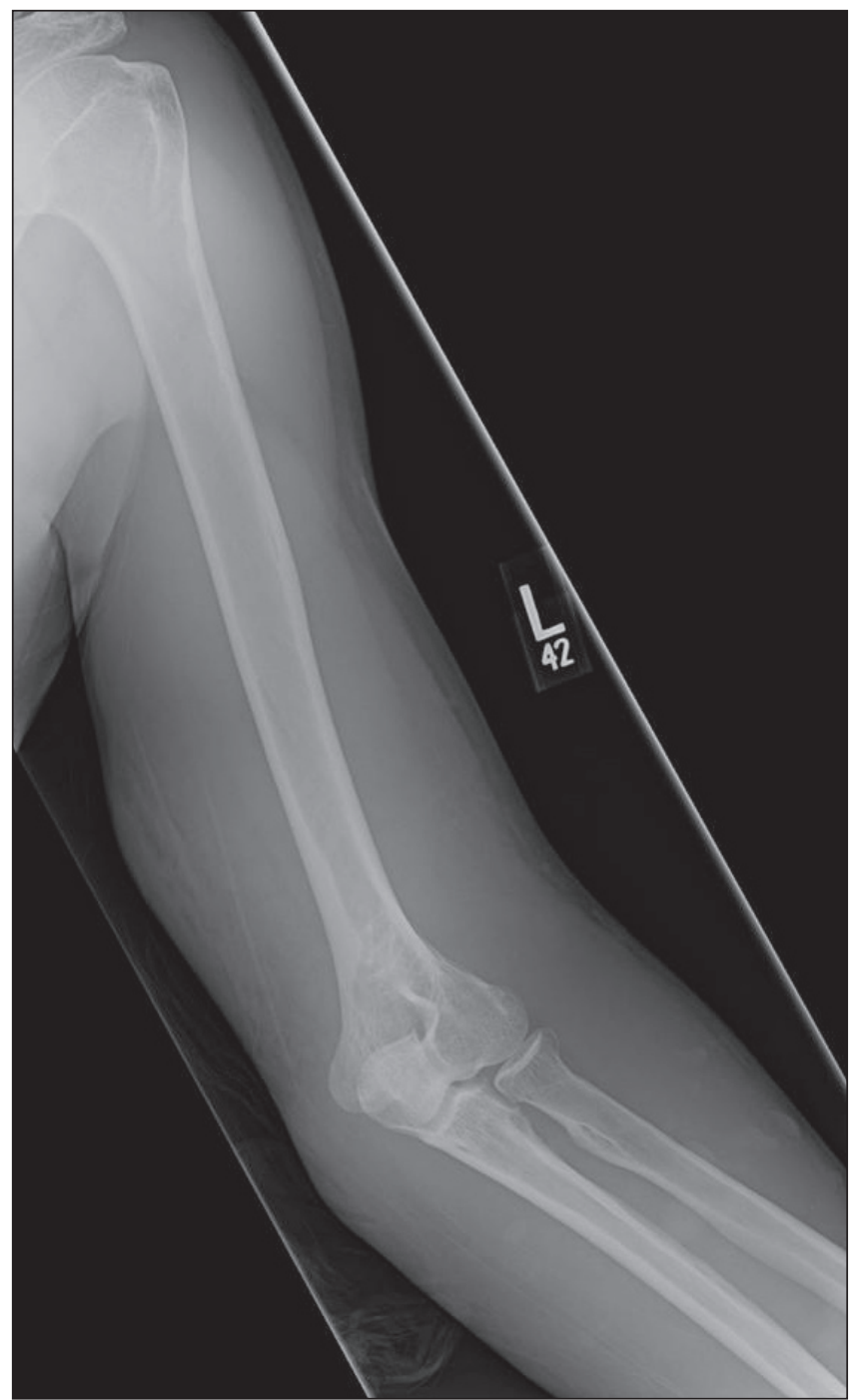

Figure 2) Radiograph of the elbow area demonstrating subcutaneous gas

In the holding area before surgery, the patient was examined again. Although the arm examination had not changed, the patient was comfortable, in no pain, had no fever, or other signs and symptoms of systemic illness.

In the operating room, a longitudinal incision over the medial and anteromedial arm was performed followed by a careful dissection. A significant amount of intradermal and subdermal clear fluid was present. The dissected tissue did not have the appearance of necrotizing fasciitis. At that time, it was decided to investigate another area of tissue on the affected forearm that had multiple bullae present. Exploration of this area yielded similar results. At this time, a carpal tunnel release was performed and was notable for significant synovial swelling. Throughout the procedure, multiple cultures were obtained in addition to fascia and skin biopsies. After extensive antibiotic irrigation and, in light of the 'benign' clinical and surgical findings, it was decided to not pursue further surgical exploration and debridement. The wounds were closed over a drain, followed by application of a dressing and splint.

Surgical pathology of intraoperative biopsies showed scant acute inflammatory infiltrate with a predominance of eosinophils, and all cultures were negative for bacterial growth. The differential diagnosis following surgery included bullous scabies, contact dermatitis, arthropod assault and Wells syndrome, which ultimately became the final diagnosis. Wells syndrome is a rare form of eosinophilic cellulitis. Diagnosis is made on the basis of lesional morphological features, peripheral eosinophilia and cutaneous histopathological features (6). The patient was started on oral prednisone and discharged to a transitional care facility on postoperative day 7 . The wounds healed uneventfully and no further treatment was necessary.

\section{DISCUSSION}

The many cases of necrotizing fasciitis published in the literature have served to establish the importance of a low threshold for aggressive surgical treatment for this condition $(3,7)$. Nevertheless, due to the significance of aggressive excision, it is important to tailor the surgery to the clinical and operative findings. The present report describes a case of suspected necrotizing fasciitis that was treated with minimal surgery because the diagnosis was not substantiated, yielding a good result.

Previous studies have emphasized the importance of background disease in the prognosis of necrotizing fasciitis. In a study by Malik et al (8), the most important prognostic factor was the presence of diabetes, which was present in $8.82 \%$ of the 73 patients reviewed; similar results were found by Dworkin et al (9). In the presence of lack of background disease combined with a benign clinical presentation (ie, no fever, pain, etc.) some degree of caution should be entertained.

Schulz and Strauch (10) described a case of factitious necrotizing fasciitis. Similar to our patient, she presented with a benign general clinical examination and no evidence of infection was found during explorative surgery. Again, this was similar to our case, as were the negative Gram stains sent during the procedure.

In conclusion, although rare, there are presentations that are similar to necrotizing fasciitis and are relatively benign. Caution with surgical debridement should be used when presented with a benign general clinical presentation and no intraoperative evidence of infection. 


\section{REFERENCES}

1. Stone DR, Gorbach SL. Necrotizing fasciitis. The changing spectrum. Dermatol Clin 1997;15:213-20.

2. Dellinger EP. Severe necrotizing soft-tissue infections. Multiple disease entities requiring a common approach. JAMA 1981;246:1717-21.

3. Orlando A, Marrone C, Nicoli N, et al. Fatal necrotising fasciitis associated with intramuscular injection of nonsteroidal antiinflammatory drugs after uncomplicated endoscopic polypectomy. J Infect 2007;54:e145-8.

4. Green RJ, Dafoe DC, Raffin TA. Necrotizing fasciitis. Chest 1996;110:219-29.

5. Kotrappa KS, Bansal RS, Amin NM. Necrotizing fasciitis. Am Fam Physician 1996;53:1691-7.
6. Gilliam AE, Bruckner AL, Howard RM, et al. Bullous "cellulitis" with eosinophilia: Case report and review of Wells' syndrome in childhood. Pediatrics 2005;116:e149-55.

7. Cheung JP, Fung B,Tang WM, et al. A review of necrotising fasciitis in the extremities. Hong Kong Med J 2009;15:44-52.

8. Malik AM, Sheikh S, Pathan R, et al. The spectrum of presentation and management of Fournier's gangrene - an experience of 73 cases. J Pak Med Assoc 2010;60:617-9.

9. Dworkin MS, Westercamp MD, Park L, et al. The epidemiology of necrotizing fasciitis including factors associated with death and amputation. Epidemiol Infect 2009;137:1609-14.

10. Schulz BM, Strauch RJ. A case of factitious subfascial emphysema. Orthopedics 2008;31:495. 